\title{
PHENOMENAL PROPERTIES ARE LUMINOUS PROPERTIES
}

\author{
GEOFFREY HALL
}

\begin{abstract}
What is the connection between having a phenomenal property and knowing that one has that property? A traditional view on the matter takes the connection to be quite intimate. Whenever one has a phenomenal property, one knows that one does. Recently most authors have denied this traditional view. The goal of this paper is to defend the traditional view. In fact, I will defend something much stronger: I will argue that what it is for a property to be phenomenal is for it to be a (consistent) property one must know oneself to have when on has it. As we will see, this theory has a number of surprising and welcome upshots, suggesting that the traditional view has been unjustly maligned.
\end{abstract}

\section{INTRODUCTION}

Theories of phenomenal consciousness divide into first order and higher order varieties . $^{1}$ More often than not, however, proponents of both varieties unite in rejecting a luminous conception of phenomenal features according to which, roughly, they comprise all and only those features that one couldn't have without being aware that one has (or at least without being in a position to be aware that one has).2 Proponents of first order varieties reject such a conception because they reject any constitutive link between consciousness and epistemic properties $3^{3}$ Thus, according to Dretske,

Failure to understand how [an experience can be conscious without anyone being conscious of having it] constitutes a failure to understand what makes something conscious and, hence, what consciousness is. (1993, p. 263)

\footnotetext{
${ }^{1}$ Here is a partial list of works defending first-order theories: Seigel 2010, Speaks 2015, Byrne 2001, Pautz [2010, Dretske 2000, 2003, Tye 1995, and Chalmers 2004. And here is a partial list of texts defending higher order theories: Rosenthal 2004, 2005, Carruthers $2005 ;$ 2016, Lycan 1996, and Armstrong 1968. \begin{tabular}{l|l|l|l|l|l|l|}
${ }^{2}$ See Williamson & 2000, & Weatherson & 2004 & Berker 2008, and Srinivasan & 2015 & for discussion. Also Lewis
\end{tabular} 1996 p. 553.

${ }^{3}$ See in particular Dretske $1993,2006$.
} 
Proponents of common varieties of higher order theses about consciousness reject the luminous conception because it does not respect the primary motivation for their view, namely, that one and the same feature is sometimes conscious and sometimes not. Thus according to Carruthers,

The main motivation behind higher-order theories of consciousness ... derives

from the belief that all (or at least most) mental-state types admit of both conscious and unconscious varieties. (2016)

This paper is a defense of the luminous conception of phenomenal features. Properly formulated this conception provides a simple, elegant and (arguably) reductive theory of the phenomenal that has quite a bit more going for it than has often been supposed. I formulate the theory in $\S 2$ and situate it within the literature. In $\S 3$, I provide several novel arguments for the view and engage in some light theory building to illustrate potential applications. There have been many objections to this view in the literature. Some of them seem to me to have rather straightforward responses; some less so. In $\S 4$, I formulate and respond to what I take to be the most pressing objections to the theory.

\section{Phenomenal Properties as Luminous Properties}

Let's start with some initial definitions to fix ideas. A phenomenal property is a property that there is something it is like for one to have. Being in pain, for instance, is a phenomenal property since there is something that it is like to be in pain. Having brown hair, on the other hand, is not a phenomenal property, since one can have this property without being conscious at all. Say that a property is luminous just in case having that property entails knowing that you have it..$^{4}$ Finally, say that a property is consistent if it does not entail

\footnotetext{
${ }^{4}$ The term 'luminous' was introduced by Williamson (2000). Williamson talks of luminous conditions (triples of worlds, times and subjects), I talk of luminous properties. This is because the subject of the paper is phenomenal properties. One could approach phenomenal properties via luminous conditions in a roundabout way (somewhat similarly to the way in which Williamson approaches narrow and broad states in terms of narrow and broad conditions). But I see no reason in particular to do this. The focus on properties instead of conditions also helps avoid potential counterexamples to the thesis I will defend.
} 
every property: $5^{5}$ According to the luminous conception of phenomenal properties, a property is phenomenal if and only if it is consistent and luminous.

But the thesis is not just that phenomenal properties happen to coincide with the consistent luminous properties. The thesis I intend to defend is more radical: being consistent and luminous is just what it is to be phenomenal. In particular, I aim to defend the following metaphysical analysis:

$\boldsymbol{L} \boldsymbol{C}$ For any property $F$, for $F$ to be phenomenal is for $F$ to be a consistent luminous property $]^{6}$

If mutually entailing properties are identical, then since knowing that one is $F$ entails being $F$, the thesis admits of an equivalent and illuminating definition.

For any $F$, for $F$ to be phenomenal is for $F$ to be consistent and such that to be $F$ is to know the you are $F \square^{7}$

\footnotetext{
${ }^{5}$ This paper takes property entailment as primitive. I will suppose that if $F$ entails $G$ then necessarily everything is necessarily $G$ if $F$ but remain, for the most part, agnostic on the converse. In various places in what follows I will make assumptions about what entailment is like. I will flag these assumptions when made. I will also remain agnostic on what properties are. My preferred framework is to treat property talk as shorthand for sentences that involve quantification into predicate position. So regimented 'being phenomenal' is properly treated as a higher-order predicate: a 'predicate' that combines with a predicate to give a sentence. But these issues are mostly orthogonal to the subject of this paper.

${ }^{6}$ When I say that $F$ entails knowing that one is $F$, I do not mean that necessarily any person who is $F$ knows that they are $F$. Rather I mean that necessarily anything whatsoever that is $F$ knows that it is $F$. This avoids possible counterexamples like existing or being self identical. Perhaps all persons automatically count as knowing that they are identical to themselves. But self identity does not entail knowledge of such identity: ordinary objects like rocks and trees are self identical but do not know anything. I should also note that the thesis $L C$ could be true without being knowable a priori. Thus $L C$ does not automatically face the 'distinct existence argument' which turns on the claim that one can conceive of having a phenomenal property without the corresponding knowledge (see Stoljar 2016.) All that this argument establishes is that $L C$ is not a priori true. Without substantial assumptions connecting conceivability and metaphysical possibility, it does not refute $L C$.

${ }^{7}$ Let $\ulcorner C(F)\urcorner$ abbreviate $\ulcorner\mathrm{F}$ is consistent $\urcorner$ and $\ulcorner K(x, p)\urcorner$ abbreviate $\ulcorner x$ knows that $p\urcorner$. Define $K^{*}$ to be the relation that obtains between oneself and a property if one knows oneself to have that property:
}

$$
K^{*}:=\lambda F x K(x,(F x))
$$

Then idea is that the phenomenal properties are precisely the consistent fixed points of $K^{*}$ :

$$
\text { Phenomenal }=\lambda F\left(C(F) \wedge K^{*}(F)=F\right)
$$

(Note that on a coarse grained conception of properties the property of sitting and not sitting may well be identical to the property of knowing that one is sitting and not sitting since both are impossible to have. Thus the requirement that the properties in question be consistent is crucial to avoid such counterexamples.) 
On this conception of phenomenal properties, they are completely pinned down by their distinctive epistemic role. Sometimes in what follows I will suppose that properties are coarse grained in this way, though in general not much will depend on this. If we do suppose that properties are coarse grained in this way, it simplifies some aspects of the discussion, but it is by no means required by the luminous conception of phenomenal features.

The thesis $L C$ provides necessary and sufficient conditions for a property to be phenomenal in terms that do not presuppose or employ phenomenal notions. Indeed if correct it tells us what it is for a property to be phenomenal in terms that do not presuppose or employ phenomenal notions. The relevant notion of entailment is meant to be a worldly or metaphysical notion of entailment. Whether one property entails another is not a matter of the phenomenal properties of any actual or possible agent. Being $F$ entails being $G$ only if it is necessary that something is $G$ if it is $F$, where the sense of 'necessity' at issue is a broad objective necessity rather than an epistemic one 8 More controversially, whether some proposition is known is not in general a matter of the phenomenal properties of any actual or possible agent. It is consistent to suppose a world has knowers at a given time even if no one at that world has any phenomenal properties at that time (perhaps all knowers fall into a dreamless sleep, for instance). If knowledge iterates and so knowing $p$ entails knowing that you know $p$, then according to $L C$ knowing $p$ is phenomenal for any $p$. This would strain the sense of 'phenomenal' at issue since for many propositions there is intuitively nothing that it is like to know them. The motivations that I take to favor $L C$ are consistent with knowledge failing to iterate. In what follows I'll suppose that knowledge does fail to iterate $!^{9}$

Supposing that there are phenomenal properties, it is of course a consequence of $L C$ that we sometimes do know that we have them. Since pain is a paradigmatic phenomenal property, $L C$ implies that we sometimes know that we are in pain. Wittgenstein famously declared the assertion 'I know I am in pain' to either be nonsense or else simply an elliptical

\footnotetext{
${ }^{8}$ Williamson 2016.

${ }^{9}$ More generally, this thesis has implausible consequences when combined with any view according to which, for some dispositional mental state $F$, being $F$ requires knowing that one is $F$. My own view is that no such thesis is plausible enough on its own to rule out $L C$, and for the purposes of this paper I will suppose that one can always fail to know that one is in some dispositional mental state.
} 
way of asserting 'I am in pain' 10 Note that if being in pain just is knowing that one is in pain, then anyone who asserts that they know they are in pain asserts that they are in pain. So in some sense $L C$, when combined with a coarse grained account of properties, vindicates the letter of Wittgenstein's view. But the thesis, as I intend it, is incompatible with the spirit of Wittgenstein's view. On my view, knowledge is a relation between individuals and propositions. To bear the knowledge relation to the proposition that grass is green is to know that grass is green and to bear it to the proposition that one is in pain is to know that one is in pain. $L C$ is a thesis about that relation. It states that having a phenomenal property $F$ entails bearing the knowledge relation to the proposition that one is $F$. Thus on my view, we often, indeed always, know that we have phenomenal properties in the ordinary sense of 'knows' in which it is also true that we often know facts about the weather11

Many philosophers are familiar with both the notion of a luminous property (or related notions) and the notion of a phenomenal property. Moreover, assertions that phenomenal properties happen to be luminous or are luminous because they are phenomenal are familiar albeit controversial. But the claim that being phenomenal consists in being luminous might seem a bit jarring. So before I get to what I take to be the strongest arguments in favor of the analysis, I want to highlight several traditions of thinking on the phenomenal with which $L C$ is congruous.

Consider first an overly simplistic higher order thought (HOT) theory of phenomenal properties according to which for a property $F$ to be phenomenal is for one to be aware that one is F. Mundane counterexamples to this thesis come from properties like being a human being, having black hair and other obviously non-phenomenal properties one is aware that one has. A standard fix is to put some extra conditions on the property $F$. For instance, we might say that a property $F$ is phenomenal if being $F$ is a mental state and, moreover, one is aware that one is F. One's phenomenal properties are all and only the mental states that

\footnotetext{
${ }^{10}$ See Wittgenstein 1953 , section 246.

${ }^{11}$ The thesis $L C$ may of course be incompatible with some specific analyses of knowledge, for example it may be incompatible with certain tracking accounts of knowledge. On my view, knowledge is a factive mental state of some kind that is familiar enough to reason about absent any specific analysis. See Williamson 2000 for this conception of knowledge.
} 
one is aware that one has. Perhaps further conditions can be put on how that awareness is generated and what kind of mental state being $F$ is supposed to be.

One immediate problem with this line of thought is that the analysis of the phenomenal now makes reference to the somewhat unclear notion of a mental state. Thus in order for HOT to offer any kind of illuminating account of the phenomenal it has to be supplemented with an account of what it is for a property to be a mental state. $L C$ can be seen as a way of getting around the mundane counterexamples to HOT without appealing to some unexplained notion of a mental state. The phenomenal properties are not merely the ones that one is aware of, but the ones that one cannot help but be be aware of ${ }^{12}$ There being something that it is like to be $F$, according to $L C$, consists in the fact that being $F$ and being aware that you are $F$ are one and the same 13

$L C$ offers a plausible explanation to those who think that phenomenal properties and beliefs are sufficiently tightly connected so that having the phenomenal property entails believing that one has the phenomenal property. ${ }^{14}$ If having the phenomenal property simply is knowing that one has the phenomenal property, then provided that knowledge entails belief, we have a plausible explanation of the connection. $L C$ will also be an improvement on those views that take phenomenal properties to be those such that to have them is just to believe that you have them. For instance, David Lewis expresses sympathy for this thought when discussing experiential properties:

\footnotetext{
${ }^{12}$ Sometimes I'll use talk of awareness in place of talk of knowledge when it seems natural to do so. The official formulation though is in terms of knowledge. $L C$ can be brought closer to traditional HOT theories if we combine it with the thesis that knowing $p$ is a mental state for any $p$. My own view is that the application of any stative propositional attitude to a proposition (in its "second" argument place) should result in a mental state, but this is not required to accept $L C$. See Williamson 1995, Williamson 2000, ch. 1, and Nagel 2013. Since the notion of awareness at issue in this paper is always relational, this also distinguishes the view defended here from a somewhat similar thesis defended by Montague (2016) according to which awareness entails awareness of awareness.

${ }^{13}$ As mentioned above one reason not to take this route is that that it does not respect the standard HOT claim that some properties can have the property of being phenomenal contingently, at least not given some standard and plausible assumptions. Suppose that $F$ is phenomenal and so consistent and such that $F=K^{*}(F)$. Since, plausibly, $F$ is necessarily consistent if consistent and necessarily identical to $K^{*}(F)$ if identical to $K^{*}(F)$ it follows that necessarily $F$ is consistent and such that $F=K^{*}(F)$. Given the further claim that metaphysical analyses are metaphysically necessary it follows that necessarily $F$ is phenomenal.

${ }^{14}$ For relevant discussion see Weatherson 2004 and Berker 2008.
} 
I rather think that an experience of a certain (suitable) kind and a belief that one is having an experience of that kind are one and the same thing. 1999 , p. 6)

But there is always a potential worry with these views that one could mistakenly take oneself to have a phenomenal property that one does not have. Indeed one of the main problems for higher order thought theorists is the contention that it makes higher order misrepresentation impossible ${ }^{15} L C$ avoids these problems by formulating the thesis in terms of knowledge instead of the non-factive attitudes of thought and belief. ${ }^{16}$

Let me be clear that these are not the reasons why I think one should accept $L C$. Both HOT and doxastic phenomenal connections are just too controversial to motivate its acceptance. The purpose of mentioning them here is just to show that $L C$ is a natural principle to accept if one has sympathies with these research programs since in the one case it captures the intuition that being phenomenal has something to do with higher order awareness without recourse to new primitives and in the other offers explanations of propositions that some have been disposed to accept.

\section{Motivations}

So why should we accept the luminous conception of phenomenal properties? On my view, the strongest motivation for $L C$ is that it is a simple, strong and perspicuous theory. Below I will outline three specific manifestations of this. In overview: $L C$ unifies and explains attractive theses in epistemology by giving phenomenal properties a distinctive evidential role; $L C$ is what we might expect to hold given a functionalist theory of mind according to which mental states are identified by their functional roles; and finally, and perhaps most importantly, $L C$ offers a route to something like a reductive analysis of consciousness in non-phenomenal terms. This seems to me a welcome and surprising prediction that should be of interest to philosophers who are ultimately unconvinced.

\footnotetext{
$\overline{15}$ See $\overline{\text { Byrne }} 1997$ and Neander 1998.

${ }^{16} \mathrm{It}$ is consistent to hold that $a$ believes that $a$ is $F$ when $a$ is not $F$ even if being $F$ is luminous.
} 
3.1. Epistemology and Phenomenal Properties. The following three principles have received quite a bit of defense within the literature on epistemology: 17

Phenomenal Conservatism: For any $P$, if it seems to one that $P$, then one is justified in believing that $P$.

Evidentialism: For any $P$, if one is justified in believing that $P$, then the proposition that $P$ is supported by one's evidence.

$\mathrm{E}=\mathrm{K}$ : For any $P$, one knows that $P$ if and only if the proposition that $P$ is part of one's evidence.

Generally those who accept Phenomenal Conservatism reject Evidentialism and E $=\mathrm{K}$. However, $L C$ provides a way in which the theses can all come out true. For suppose that it's seeming to one that $P$ is phenomenal. Hence, whenever it seems to one that $P$, one knows that it seems to one that $P$. So by $\mathrm{E}=\mathrm{K}$, it's seeming to one that $P$ is part of one's evidence. Since, plausibly, the proposition that it seems to one that $P$ raises the probability that $P$, this allows us to hold Phenomenal Conservtism without giving up EVIDENTIALISM 18

Here is another way to put the argument. If Phenomenal Conservatism, EvidenTIALISM and $\mathrm{E}=\mathrm{K}$ are true, then whenever it seems to one that $P$, that $P$ is supported by what one knows. But if this holds for any case, the only relevant proposition to know that can support $P$ will be the proposition that it seems to one that $P$. Thus the conjunction of these three principles naturally leads to the claim that seemings are luminous. Since seemings are paradigms of phenomenal states, this accords with the requirements of $L C$.

Of course many will be inclined to reject one of the above principles precisely because they do not think seemings luminous. But each of the above principles has quite a bit

\footnotetext{
${ }^{17}$ For discussion of Phenomenal Conservatism see Pryor 2000 and Huemer 2001, 2007. For a defense of Evidentialism see Feldman and Conee 1985 and Williamson 2000, ch. 9. Williamson (2000, ch. 9) also defends $\mathrm{E}=\mathrm{K}$.

${ }^{18}$ Of course one might give up one of these principles for different reasons. Bacon (2014), for instance, shows that there is a tension between EvidEnTIALISM and $\mathrm{E}=\mathrm{K}$ given an anti-skeptical epistemology together with a probabilistic analysis of support. These worries do not effect my overall case since the hard cases are those concerning knowledge of the future, not knowledge of one's own present phenomenal state.
} 
going for it. The theory consisting of $L C$ and the above three principles gives phenomenal properties a distinguished evidential role. For any phenomenal property $F$, that one is $F$ is part of one's evidence if and only if one is $F$. Consequently when evaluating whether a subject is justified in believing a proposition, we can always take into account how things stand phenomenally with that subject. The result is a knowledge first view that validates phenomenal conservatism and recognizes a special distinguished role for phenomenal evidence in the justification of belief. ${ }^{19}$

3.2. Phenomenal Properties and Functionalism. Another motivation for $L C$ stems from the plausibility of functionalism. While sameness of functional role might not suffice in every case for sameness of property, it is certainly evidence of this. And it seems quite plausible that for any phenomenal property $F$, being $F$ and knowing that you are $F$ will play the same functional role. Consider the state of being in pain. A sort of standard gloss of its functional role is that it is a

a state that tends to be caused by bodily injury, to produce the belief that something is wrong with the body and the desire to be out of that state, to produce anxiety, and, in the absence of any stronger, conflicting desires, to cause wincing and moaning. (Levin, 2018)

But this functional role is also plausibly played by the state of knowing that one is in pain. If one were to guess which state was being functionally characterized in the above quotation, it is unclear what grounds there would be for saying it was pain as opposed to knowledge of pain.

Perhaps one could object by saying that knowledge of pain might lead one to, for instance, take pain killers but mere pain without knowledge of pain would not. But we should be careful to distinguish knowing that one is in pain under the guise of the sentence ' $\mathrm{I}$ am in pain' and knowing that one is in pain under some guise or other. If I am in pain, I know

${ }^{19}$ The view thus vindicates Schellenberg's 2013, 2016) contention that subjects in indiscriminable cases can share phenomenal evidence while still differing in factive evidence, although it does so in a way that is not congenial to her overall project. 
that I feel like this. I know this even if I am unsure whether to describe how I am feeling using the word 'pain'. But since I am indeed in pain, what I know when I know that I feel like this is that I am $F$, where $F$ is the property of being in pain.

Others might object that it is impossible for being in pain and knowing that one is in pain to have the same functional role since sometimes being in pain causes one to know that one is in pain, but knowing that one is in pain can never cause itself. I of course deny the view that in general the link between knowing that one is in pain and being in pain is causal. But there isn't any general case for that view. It is commonplace for one to know that $p$ despite its being false that one believes that $p$ because $p$, especially where the sense of 'because' is causal. For instance, we commonly have knowledge of mathematical facts, moral facts, and facts about the future. But presumably such facts cannot be part of the cause in our beliefs concerning them.

Now of course, some will object to this argument on the grounds that some creatures have pain while lacking knowledge altogether and so trivially pain and knowledge of pain differ in functional role in at least some creatures. I will address the case of nonhuman animals in the next section. Here I am only claiming that at least in human adults, our description of the functional role of pain largely overlaps our description of the functional role of knowing that one is in pain, which goes some way towards confirming $L C$.

3.3. LC as an account of what it is to be conscious. I take the above considerations to provide some initial motivation for endorsing $L C$. They are by no means knock down arguments. My overall argumentative strategy, however, is abductive. The theory comprised of $L C$ with plausible auxiliary assumptions recommends itself on the basis of simplicity and perspicuity. A case in point is that $L C$ together with plausible and shared assumptions affords us something like an account of what it is to be conscious that does not use or presuppose any phenomenal notions.

Suppose that the property of being conscious is the most general phenomenal property, that phenomenal property one has if one has any phenomenal properties at all. Then the 
thesis $L C$ can be used to uniquely pin down consciousness in non-phenomenal terms: the property of being conscious is the unique consistent luminous property that is entailed by every consistent luminous property. I think this is a very interesting and striking accomplishment. With very minimal resources, $L C$ delivers an account of what it is to be conscious.

One might object that being conscious is not the most general phenomenal property on the grounds that it is not phenomenal. Some authors exclude consciousness from the category of the phenomenal even though they include more specific determinates. Speaks (2015), for instance, stipulates that 'phenomenal property' means 'determinate of the property of being conscious'. Since nothing is a determinate of itself, being conscious is not phenomenal on Speaks' account. I am working with a broader conception of phenomenal properties as simply "properties for which there is something that it is like to have." Being conscious is not obviously excluded from that category. The determinates of such determinables may still form a natural class and thus there is not much theoretical cost if some generalizations about the phenomenal need to be restricted to determinate phenomenal properties. Additionally, even without the assumption that being conscious is phenomenal, we may still be able to extract an account of what it is to be conscious. For instance, if properties are relatively coarse grained, we can pick out consciousness as the least upper bound of the phenomenal properties under entailment. Consciousness will be the unique property entailed by every phenomenal property that moreover entails every property entailed by any phenomenal property. ${ }^{20}$ If we call the least upper bound under entailment of some properties the disjunction of those properties, then the thesis can be equivalently formulated as: to be conscious is to have the disjunction of the consistent luminous properties ${ }^{21}$

\footnotetext{
${ }^{20}$ Suppose that properties form a complete lattice with respect to the ordering of entailment. This would be guaranteed by the theory that properties are functions from worlds to extensions, though is also compatible with more fine grained accounts of properties. Where $P$ is the set of all phenomenal properties, the proposal is then that the property of being conscious is the join $\bigvee P$. Given $L C$, the set $P$ has an "intrinsic" description in non-phenomenal terms. The notion of a join is also defined non-phenomenally. Thus given $L C$, being conscious can be singled out by an intrinsic, non-phenomenal description.

${ }^{21}$ Note that if being $F$ and being $G$ are consistent and luminous it does not automatically follow that being $F$ or being $G$ is consistent and luminous. If one is $F$ then one knows one is $F$ and is $F$ or $G$. But in order to know one is $F$ or $G$ requires another inference. Thus this proposal is compatible with those who want to exclude the property of being conscious from the phenomenal.
} 
3.4. Knowledge and phenomenal intentionality. One objection someone might have to this line of thought is that since the proposed definition of consciousness makes reference to knowledge, it cannot be claimed to be a reductive definition at all since ultimately knowledge should be defined in terms of the notion of a phenomenal property. My own view is that the notion of knowledge is quite a bit clearer than than the notion of a phenomenal property and thus we should welcome an analysis of the latter in terms of the former. Some philosophers disagree. According to the phenomenal intentionality theory the phenomenal is a "main ingredient" in the analysis of intentional states more broadly There is a potential for conflict: according to $L C$, the phenomenal is partly constituted by knowledge. According to the phenomenal intentionality theory, knowledge is partly constituted by the phenomenal (since all intentional states are). But if $A$ is partly constituted by $B$ then $B$ is not partly constituted by $A$. Thus $L C$ is not compatible with the phenomenal intentionality theory.

On closer inspection the conflict is seen to be illusory. For instance, Bourget and Mendelovici (2018) offer three different formulations of the theory, the strongest of which they call "Strong PIT":

Strong PIT: All intentional states are phenomenal intentional states.

Since knowing that one is $F$ is certainly an intentional state, Strong PIT entails that the explanation of the phenomenal offered by the luminous conception makes reference to a particular phenomenal state. But there is nothing in general troubling about an analysis of being $F$ that mentions some particular $F$. There may even be reductive analyses of various properties that mention instances of those properties. For example, consider the analysis of the property of being an even integer:

for an integer $n$ to be even is for there to be some integer $k$ such that the product of the integer 2 with $k$ is identical to $n$.

This analysis entails that 2 is itself an even integer, and thus that the analysis of being an even integer makes reference to a particular even integer. Nevertheless, the analysis is illuminating and in some sense reductive. Learning this analysis can put someone in a 
position to understand 'even integer' who did not grasp that notion prior to learning the definition.

The luminous conception of phenomenal properties thus has some distinctive benefits: it allows for a synthesis in epistemology of views usually thought to be in opposition, it is confirmed by our failure to isolate different functional roles for phenomenal properties and our knowledge of phenomenal properties, and it provides a simple and perspicuous account of the phenomenal. I now want to turn to what I take to be the more salient objections to the view that have been offered in the literature.22

\section{OBjections And Replies}

4.1. Accessibility. The following story seems possible. Late for work I search my room desperately for my one missing shoe. After completing what I take to be a thorough search and turning up empty, I ask my roommate for help. Upon entering, they notice the shoe, lying on top of my bed. In this situation, surely I saw the shoe. It was there in plain sight, so to speak. When I was searching, as my eyes scanned the room, there was a point when I looked right at it. Eyes wide open, one could have drawn two straight lines, roughly five feet in length, from each of my eyes to the shoe. It seems perfectly natural to say in such a situation that while I had a visual experience of the shoe, I didn't know that I did. If I had known at the time that I had this experience, why did I not act on this knowledge? Why did I continue to search the room? Why did I utter the sentence 'I cannot find my shoe! I looked everywhere in my room and did not see it!?

If we attempt to turn these rhetorical questions into explicit arguments, we find that they rely on premises that, while somewhat plausible, are open to question. For instance, one

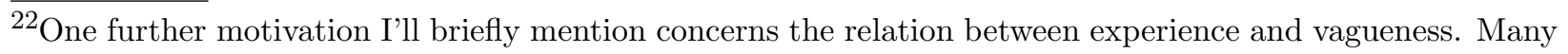
authors have expressed sympathy for the thesis that it can never be borderline whether something is conscious (see e.g., Antony (2006, 2008) and Simon (2017)). The principle of $L C$, together with standard principles governing the relationship between borderliness and knowledge, explain why this would be so. For suppose that knowledge precludes borderlineness: if one knows that $p$ then it is not borderline whether $p$. Then if being conscious is a phenomenal property, $L C$ entails that whenever one is conscious, it is not borderline whether one is conscious. Say that it is determinate that $p$ if and only if $p$ and it is not borderline whether $p$. Then we can put this conclusion as follows: if one is conscious, it is determinate that one is conscious.
} 
might attempt to argue that (I) I had an experience of the shoe, and (II) if I had known that I had an experience of the shoe, I wouldn't have continued to search the room, but (III) I did continue to search the room, so (IV) I did not know that I had an experience of the shoe and thus (C) I had an experience of the shoe and I did not know that I had an experience of the shoe. If having an experience of the shoe is a phenomenal property, we can then turn this into an argument against $L C$.

For the purposes of this section I'll grant that having an experience of the shoe is phenomenal. We can question premise (II). There are plenty of cases in which it is plausible to say that one knows something despite the fact that they failed to act on what they knew. Not all of one's knowledge is actionable in every case. More generally, it is not true that if one knows that $p$, then the proposition that $p$ is accessible in the sense of being available for use in theoretical and practical reasoning in every single case.

Take the following example. I know, and have known for many years, what my social security number is, despite the fact that there have been instances where I was unable to recall the number. Thus plausibly there are cases in which I know that my social security number is $x$ without being able to recall that it is $x$. If there are cases in which one knows that $p$ despite being unable to recall that $p$, then we should expect cases in which one does not act as if $p$ even though they know that $p$. If one knows that $p$, then perhaps they have a disposition to act as if $p$. But this does not mean the disposition will manifest itself in every case. This just goes to show that the premise 'If I had known that I had an experience of the shoe then I wouldn't have continued to search the room' is open to question. We can further solidify this judgment by extending the original case given above.

Imagine that I decide to give up on the search and leave the house wearing another pair of shoes. Upon leaving, however, I suddenly recall that I did in fact see the shoe on the bed. This strikes me as a commonplace experience. I cannot recall what I did not already know. Thus I did know that I saw the shoe, I just did not realize that I knew this - the knowledge I had was implicit. I say that this is possible. And if it is possible, another alternative explanation of the above case presents itself: I saw the shoe, I knew that I saw the shoe, 
but I did not attend to the fact that I saw the shoe (i.e., the knowledge I had was implicit in some sense).

Put somewhat more abstractly the response is that while the phenomena identified in the example is real, they do not provide counterexamples to $L C$. According to those who think it provides a counterexample to $L C$, they should be described as cases in which one has some phenonomenal property but fails to know; according to me they are cases in which one has some phenomenal property but fails to attend or explicitly know ${ }^{23}$ We should favor the latter description over the former because for any such case there is a case that is similar in all the relevant respects but in which the subject later recalls that they had the phenomenal property thus showing that they did in fact know they had the phenomenal property after all. The claim that one fails to explicitly know or attend is not some ad hoc posit but is rather needed to explain the phenomena.

4.2. Nonhuman Animals. Some philosophers have objected to the luminous conception on the grounds that it over intellectualizes the phenomenal. If knowing that ..F ... requires having the concept of $F$, then knowing that one is in pain requires having the concept of pain. But, these philosophers maintain, many creatures can be in pain that lack the concept of pain-perhaps some creatures can be in pain that lack concepts altogether. Even if there are no actual creatures like this, surely it is possible that something be in pain but lack the concept of pain. If that's right then $L C$ must be false.

What is it to have the concept pain? On a deflationary reading, to have the concept pain is just to be able to have beliefs about pain. So interpreted the argument might be put this way:

(1) Possibly something is in pain but is not able to believe that it is in pain.

(2) Necessarily, whatever one knows one is able to believe.

(3) Thus it is not necessary that if one is in pain one knows that one is in pain. $(1,2)$

\footnotetext{
${ }^{23}$ And hence $L C$ should be construed as the thesis that $F$ is phenomenal if it is consistent and implicitly knowing one is $F$ is being $F$. Explicit knowledge is something like attending to the fact that something is the case, implicit knowledge is simply knowledge, which may be present without one attending to the fact to what one knows.
} 
(4) If the luminous conception is true and pain is phenomenal, then necessarily if one is in pain one knows that one is in pain.

(5) Pain is phenomenal.

(6) The luminous conception is not true. (3-5)

There are more inflationary readings of concept talk. But if the deflationary argument proves to be unsound so will any version of the argument that uses some more inflated reading of concept talk.

The argument is valid. Is it sound? I won't challenge premises (4) or (5). This only leaves premises (1) and (2). Premise (2) can be motivated by a pretty straightforward argument: (i) necessarily whatever one knows one believes; (ii) necessarily whatever one believes one is able to believe. (ii) strikes me as completely obvious. What about (i)? Does knowledge entail belief? Myers-Schulz and Schwitzgebel (2013) have argued that there are cases in which someone knows a proposition despite its being indeterminate whether they believe it ${ }^{24}$ In fact they think something stronger: there is some particular case and they think that in that case they know a proposition they don't determinately believe. If that is correct, then plausibly there are cases in which it is determinate that someone knows a proposition but indeterminate whether one believes it 25 Any such case would be a counterexample to the principle that knowledge determinately entails belief. If knowledge fails to determinately entail belief then one is not in a position to know whether the above argument for (2) is sound since one is not in a position to know one of the premises.

Even if (i) is true, some philosophers do not think it should be given default status. Some recent studies by Murray et. al (2013) show that in a variety of cases, a significant minority of English speaking non-philosophers are willing to ascribe knowledge without belief. Premise (i) is not unassailable. While I am somewhat sympathetic to a conception of knowledge on which it fails to entail belief, given that the majority of philosophers accept (ii) I do not

\footnotetext{
${ }^{24}$ For a response see Rose and Schaffer 2013.

${ }^{25}$ The reason is that they are prepared to assert that in that particular case, the proposition is known. But plausibly one should not assert that which is indeterminate.
} 
want $L C$ to stand or fall with its denial. In what follows I am going to sketch a response that denies (1).

What can be said in favor of (1)? A standard motivation for premise (1) is to argue that there are actually cases of nonhuman animals who feel pain but do not believe that they feel pain. According to these objectors, the physical conditions required for pain are simpler, in some sense, than those required for belief. The behavior indicative of pain is found in very unsophisticated creatures. In these creatures, so the objection goes, there is no evidence of belief like behavior.

But there is something unstable about this argument. The very evidence that the relevant creature is in pain, it seems to me, is evidence that they believe that they are in pain (and thus able to believe that they are in pain). Here is a simple argument for this conclusion. First, we ought to favor a simple and uniform theory of human behavior according to which all behavior is explained by belief desire psychology. So in particular, pain behavior in human persons ought to be explicable in terms of their beliefs and desires. And second, similar behaviors in different species suggest similar explanations. So in particular, the evidence that nonhuman animals are in pain, namely that they exhibit similar pain behavior to us, suggests a similar explanation to ours in terms of beliefs and desires. So when one finds a creature that exhibits pain behavior, presumably that behavior is recognizable as pain behavior because it is similar to our pain behavior. But our pain behavior is often explained by our belief that we are in pain. Thus the natural conclusion is that nonhuman animals pain behavior is similarly explained.

The point can perhaps be put more simply. The objector claims that there are creatures who behave as if they are in pain, but lack beliefs. So either there is an asymmetry between the explanation of their pain behavior and ours, or else there is no uniform theory of human behavior in terms of beliefs and desires. Each of those options, it seems to me, is a theoretical cost. 
I suspect that these considerations will fail to convince someone who is already committed to (1). Many philosophers think in order know a proposition, one must grasp that proposition. In turn, in order to grasp a proposition, they think, one must have some capacity for the use of language. If we combine this view with $L C$, the result is that either, implausibly, the capacity for language is much wider than we think, or, also implausibly, the range of conscious creatures much narrower than we think. It's worth pointing out that this consequence is one that is shared by many theories of consciousness currently on offer. For example, intentionalists think that experience constitutively involves a belief-like propositional attitude. Some philosophers even think this attitude is a determinable of knowledge. Thus $L C$ isn't alone in offering a theory of experience that requires one to reject any tight connection between propositional attitudes and the capacity for language.

If propositional attitudes are not bound up with our capacity for language in any interesting sense, what are they bound up with? What is it about us and other creatures that allows us to have propositional attitudes at all? This is no doubt a difficult question and one I cannot fully answer here. However it is worth briefly sketching a picture of the propositional attitudes that sits more comfortably with $L C$, at least to illustrate that the thesis is capable of being integrated with independently motivated pictures of the mind.

In order for $L C$ to get off the ground, we need a theoretical account of knowledge that explains such knowledge independently of language. One view that I have quite a bit sympathy for is a Williamsonian conception of knowledge according to which one knows that $p$ if and only if one bears some factive mental attitude to the proposition that $p$. On this conception of knowledge, if knowing requires the capacity for language, then having factive attitudes in general would require the capacity for language. But this doesn't seem too plausible. After all, perception itself seems to involve a factive attitude. But it should be common ground that perceiving does not require the capacity for language.

Factive attitudes play an important role in the explanation of successful action. When I see that the car is coming towards me, I have the ability to base my actions on the fact that the car is coming towards me. On one view of propositional attitudes, they are posits 
in a theory of action. Factive attitudes play a distinctive role in this theory, accounting for our ability to base our actions off of certain facts, rather than simply accidentally acting in accordance with those facts. Whenever one bears some factive atttitude towards the proposition that $p$, one has the ability to base their actions on the fact that $p$. Moreover, normally, when one has the ability to base their actions on the fact that $p$, it is because one bears some factive attitude towards the proposition that $p$. Thus generally, since knowledge is the most general factive attitude, one knows that $p$ if and only if one is able to base their actions off of the fact that $p \cdot{ }^{26}$ This sits well with $L C$ since it seems quite plausible that any being that has phenomenal properties is able to base their actions on the fact that they phenomenal properties. Indeed this seems to be in some sense the point of phenomenal properties. Even for someone hostile to $L C$, it would be quite surprising to find out that there were a species of creatures who felt pain, but had no ability to adjust their actions as a result of feeling pain. If they couldn't adjust their actions accordingly, there would have been no evolutionary advantage to feeling pain in the first place.

To sum up, I want to emphasize the following point. The basic idea of my response is to first re-conceptualize the debate as being a debate about who has a better model of the actions of organisms. I suggest we adopt a uniform model in which knowledge and belief play a role in explaining the behavior of all organisms in much the same way that they explain our own. This model combines rather well this the picture that (i) knowledge is a mental state of some kind, and (ii) mental states are posits in the best overall theory of behavior of some class of entities. When thought of this way, the idea that having a phenomenal property and knowing that one has a phenomenal property go hand in hand starts to look to me pretty plausible since it is only a few steps away from the observation that organisms invariably have the capacity to act on the basis of their phenomenal properties. Thus $L C$ seems to fall out of a quite natural and uniform theory of the phenomenal properties of organisms in general. This seems to me to lessen the force of the objection from conceptual sophistication quite a bit. In effect what we have are two different theories of mental states in general. The

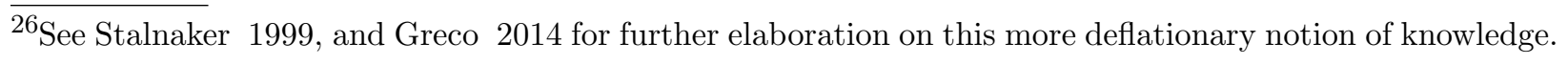


theorist who takes propositional attitude to be bound up with language must explain why that theory is better than its alternative. On my view, this is a theoretical task, and not one that can be settled easily against the view I have been sketching.

\subsection{Difference of awareness and awareness of difference. The following train of} thought has some initial plausibility:

Suppose that I present an arrangement of dots on a board in front of you. You briefly experience this arrangement before I switch the board with a new arrangement of dots. The new arrangement of dots is exactly similar to the old arrangement of dots apart from the inclusion of one extra dot. However, you fail to notice this dot. You would report that the two experiences were qualitatively indistinguishable. This certainly seems like a possible case. But given that it is possible, it would appear that there could be differences in one's perceptual experiences without any differences in one's knowledge of which perceptual experiences one is having. Since the luminous conception predicts that there cannot be differences in one's perceptual experiences-construed as phenomenal properties-without a difference in knowledge of which perceptual experiences one is having, the luminous conception is false.

This objection has been raised by Dretske in several influential papers arguing against the higher order view of consciousness. His conclusion, in his own words, is that ...there can be conscious differences in a person's experience of the world-and, in this sense, conscious features of his experience-of which that person is not conscious. If this is true, then it cannot be a person's awareness of a mental state that makes that state conscious. (Dretske, 2000, p. 132)

The argument is fallacious, at least applied to $L C$. Call the two arrangements presented 'arrangement 1' and 'arrangement 2'. Call the phenomenal property one has upon observing arrangement 1 'experiencing arrangement 1' and the phenomenal property one has while observing arrangement 2 'experiencing arrangement 2'. I will follow Dretske in supposing that experiencing arrangement 1 is not experiencing arrangement 2. The inclusion of another dot in arrangement 2 makes for a real conscious difference upon experiencing it. In the case described, there is a certain time $t_{0}$, such that

(1) at $t_{0}$, one experiences arrangement 1. 
And there is a time $t_{1}$ after $t_{0}$ with the property that

(2) at $t_{1}$, one experiences arrangement 2 .

At neither $t_{0}$ nor $t_{1}$ is one experiencing both arrangement 1 and $2 . L C$ together with (1) and (2) entails both (3) and (4).

(3) at $t_{0}$, one knows that one is experiencing arrangement 1.

(4) It is not the case that at $t_{1}$, one knows that one is experiencing arrangement 1.

That is, $L C$ predicts that a change in phenomenal properties corresponds to a change in knowledge of phenomenal properties. However, (4) does not entail (5)

(5) at $t_{1}$, one knows that it is not the case that one is experiencing arrangement 1.

Now (2), together with the luminous conception entails

(6) at $t_{1}$, one knows that one is experiencing arrangement 2

But even with (6), (3) and (4) do not deliver (5). LC does not predict that whenever there is a change in one's phenomenal properties, one knows that there is a change in one's phenomenal properties.

How does Dretske think we get to (5) from the description of the case and $L C$ ? One hypothesis is that Dretske subtly conflated positive introspection and negative introspection. Positive introspection says that whenever a certain condition obtains, it is known to obtain. Negative introspection says that whenever a certain condition fails to obtain, one knows that it fails to obtain. $L C$ entails positive introspection. It does not entail negative introspection.

Dretske sometimes puts the point as follows: there can be differences in our conscious awareness without awareness of the difference. So put, the point is ambiguous. On one reading it is true but consistent with the luminous conception. On another reading, it is false, but that reading is so hard access that it is no wonder that the sentence sounds true.

A simple model of the above situation will help bring out the ambiguity. Suppose that experiencing arrangement 1 is identical to the conjunction of $f_{1}, \ldots, f_{n}$ and experiencing arrangement 2 is identical to the conjunction of $f_{1}, \ldots, f_{n-1}, g_{n}$. Intuitively $g_{n}$ is that phenomenal property which corresponds to the extra dot that one experiences and $f_{n}$ is that 
phenomenal property associated to the blank space. When one experiences arrangement 2, "the difference in one's conscious awareness" might just be identified with $g_{n}$. Is one aware of that difference? Well if the the luminous conception is correct, then one knows that one has $g_{n}$. So there is a difference, namely $g_{n}$, such that one is aware, in some sense, of $i t$. But that is consistent with one not knowing that there is a difference i.e., not knowing that there is some phenomenal property they currently have but didn't have several moments ago. All Dretske's case shows is that there can be a difference and one not know that there is a difference. It doesn't show that there can be difference, a particular phenomenal property, despite one not knowing that one has it. There being a property that is the difference such that one knows that one has it, and one knowing that there is some property that is a difference are different cognitive accomplishments.

4.4. Anti-luminosity. A celebrated argument due to Timothy Williamson attempts to show on the basis of general structural constraints on knowledge that there are no nontrivial luminous conditions. The argument can be adapted to the present case. In this context, it is given as an argument for the conclusion that there are no consistent luminous properties. If sound, $L C$ would then have the consequence that there are no phenomenal properties.

The most straightforward adaptation makes use of the principle that knowledge requires belief that is safe from error: if one knows that $p$, then in nearby circumstances one does not falsely believe that $p .27$

More precisely:

SAFETY: For any possible situation $s$, if in $s$ one knows that $p$, then for any possible situation $s^{\prime}$ nearby $s$, in $s^{\prime}$ if one believes that $p$ then $p$.

Say that a sequence of (possible) situations $s_{1}, \ldots, s_{n}$ is problematic for a property $X$ if and only if

\footnotetext{
${ }^{27}$ In what follows I work with a rather simplified version of the argument that more closely resembles a version presented by Srinivasan (2015). Ultimately I would need to respond to the more sophisticated versions given in terms of confidence, but to do so would require more space than can be provided here.
} 
(1) In $s_{1}$, one is $X$.

(2) In $s_{n}$, one is not $X$.

(3) $s_{i+1}$ is nearby $s_{i}$ for $1 \leq i<n$.

(4) If in $s_{i}$, one knows that one is $X$, then in $s_{i+1}$, one believes that one is $X$.

Suppose that there is a sequence $s_{1}, \ldots, s_{n}$ of situations that is problematic for a phenomenal property $X$. Then it follows, given the truth of SAFETy, that $L C$ is false. Here is why. In $s_{1}$ one is $X$ and in $s_{n}$ one is not $X$ by supposition. Therefore, there is some $1 \leq i \leq n$ such that in $s_{i}$, one is $X$ and in $s_{i+1}$, one is not $X$. Since $s_{i+1}$ is nearby $s_{i}$, SAFETY guarantees that either one does not believe on is $X$ in $s_{i+1}$, or one does not know one is in $X$ in $s_{i}$. So by supposition in $s_{i}$, one does not know that one is $X$. Thus there is some phenomenal property $X$, such that possibly one is $X$ and does not know that one is $X$. Therefore, $L C$ is false.

At this point, the argument is merely schematic in character. We need to be given some reason to think that there are problematic sequences for phenomenal properties. Williamson 【2000) described the following possible example:

Consider a morning on which one feels freezing cold at dawn, very slowly warms up, and feels hot by noon. One changes from feeling cold to feeling not cold, and from being in a position to know that one feels cold to not being in a position to know that one feels cold.(2000, p. 97)

More formally, let $t_{1}, \ldots, t_{n}$ be a sequence of times at one millisecond intervals from dawn to noon. For $1 \leq i \leq n$, let $\alpha_{i}$ be a centered possible world whose time coordinate is $t_{i}$ and whose center is the agent described in Williamson's case. Then $\alpha_{1}, \ldots, \alpha_{n}$ is a candidate for being a problematic sequence for the property of feeling cold ${ }^{28}$ The basic idea, following Srinivasan (2015), is that the pairs of cases $\alpha_{i}$ and $\alpha_{i+1}$ are one's in which the subjects phenomenal properties are idiscriminable, and so that if one knows that one has the a given

\footnotetext{
${ }^{28}$ We can suppose for the sake of argument that feeling cold $i s$ phenomenal, though I suspect that it is better thought of as derivative from one's phenomenal properties rather than a phenomenal property in the strict sense.
} 
phenomenal properties in $\alpha_{i}$, and so thereby believes one has that property, then one should also believe in the next moment due to the fact that how things stand with them vis-a-vis coldness in $\alpha_{i+1}$ indiscriminable from how things stood in $\alpha_{i}{ }^{29}$,

In response to this argument I want to say three things. First, as has already been noted by Berker (2008), Weatherson (2004) and Srinivasan (2015), the judgment that condition (4) is satisfied in the above case is going to look quite a bit less plausible to the theorist who takes there to be some sort of constitutive connection between belief and phenomenal properties. The justification for (4) is something like this: if I know that I have some phenomenal property $X$ in $\alpha_{i}$, then since $\alpha_{i+1}$ is indiscriminable from $\alpha_{i}$ we would expect the belief to remain since our beliefs are governed by dispositions to respond to similar circumstances in similar ways. Moreover, since we are beings with limited powers of discrimination, my dispositions to believe cannot be so finely individuated so as to be activate belief in one situation without thereby activating belief in any indiscriminable situation (at least generally). Now this argument is of course just a sketch, though versions of it have been developed at more length by, for instance, Srinivasan (2015). The important point is that if one is already sympathetic to $L C$, one is not going to accept this view that one's knowledge of $X$ requires some "basis," nor would one accept that one's powers of discrimination are "limited" with respect to phenomenal properties. If, for any phenomenal property $X$, being $X$ is knowing that one is $X$, there is no limitation with respect to our ability to discriminate phenomenal properties. Additionally, if being $X$ is knowing that one is $X$, one's belief is automatically induced by simply having the phenomenal property. The explanation of one's belief in $\alpha_{i}$ is not that one is disposed to respond to one's phenomenal properties in certain ways in certain circumstances. The explanation is simply that one has the phenomenal property, which, given $L C$, raises the probability that one believes one has the property to 1.

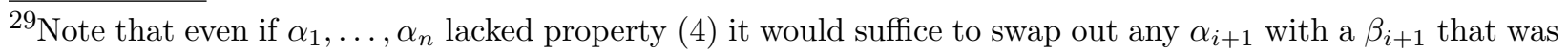
phenomenal indiscriminable from $\alpha_{i+1}$ but is such that, if one knows in $\alpha_{i}$, one believes in $\beta_{i+1}$ (provided of course there is such a $\beta_{i+1}$. Note though that it is a substantive claim that $\beta_{i+1}$ must thereby be nearby. For further discussion see the principle $\left(\right.$ BEL $\left.^{*}\right)$ in Srinivasan (2015)
} 
This response merely points out that in order to convince someone who already accepts $L C$, more needs to be said to motivate the claim that condition (4) is met in the above scenario. However there are also two positive reasons for resisting Williamson's anti-luminosity argument that the proponent of $L C$ can appeal to.

Williamson (2000) is known for advocating the view that knowledge is the most general factive mental state. That is, for any proposition $p$ and factive mental state $V$, if one $V$ s that $p$, then one knows that $p$. So if the above situation describes a sequence that is problematic for the property of being cold, and knowledge is the most general factive mental state, it follows that there is a possible situation in which one is cold, but does not $V$ that one is cold, for any factive mental state $V$. But as was also noted by Williamson (2000, ), 'one could feel that' expresses a factive attitude. Thus the anti-luminosity argument implies, given other theses Williamson accepts, that it is possible that one is cold but could not feel that they were cold. This strikes me as being inconsistent with Kripke's content that being cold just is feeling cold. Perhaps one could say that they felt cold but could not feel that they were cold. But I have a hard time parsing that sentence in a way that sounds consistent.

The point is not just restricted to feelings. Consider a situation in which one experiences a red chip that slowly turns from red to blue. At the beginning of the day, it is red. At the end it is blue. Suppose moreover that one's experiences is perfectly calibrated to track the color of the chip. It represents the chips as red if and only if the chip is red throughout the day. Since it is blue at the end of the day, there is some last moment $t_{n}$ at which it is red. Thus at $t$ one's experience represents the chip as red but at $t_{n+1}$ the chip is not red. Could one see that the chip was red at $t_{n}$ ? I'm inclined toward the view that they could. Since one is perfectly tracking the color of the chip, it is red, and one's experience represents that it is red, one sees that it is red. But if one could see that it is red, then one knows that it is red (since knowledge is the most general factive attitude). Thus one knows that it is red despite the fact that in the next moment it is not red. But it seems to me that one's epistemic situation with respect to the proposition that one is cold in Williamson's case is analogous to one's epistemic position with respect to the proposition that the chip is red in 
this case. Thus it seems to me that either we should reject SAFETY, or else say that in these cases one's belief in the given proposition correlates perfectly with one's knowledge of the given proposition 30

Now in some ways this could be read as more of an ad hominem against Williamson. But it is not merely an ad hominem. I myself find the characterization of knowledge as the most general factive mental state as somewhat compelling. If there is a most general factive mental state, we might expect our word 'knows' to pick it out for reasons relating to reference magnetism. Even if it doesn't, provided that the most general factive mental state plays some of the functional roles often attribute to knowledge, we could still formulate a principle like $L C$ in terms of this most general factive attitude that would share with $L C$ many of its benefits. That would then represent a natural fallback position for the proponent of $L C$.

This response doesn't say which premise of Williamson's argument to reject. Instead it points out that the conclusion conflicts with some other plausible theses, and so if we believe these other plausible theses, we should reject at least one of the premises of Williamson's argument. The weakest premises in my view are SAFETy together with the idea the idea that the sequences in questions jointly satisfy (3) and (4). For instance, in the above case in which the chip turns from red to blue, it seems to me that seeing that it is red is compatible with its being blue in the next instance. But if we appeal to the idea that our beliefs are governed by imprecise dispositions, then for similar reason as before we should be able to construct the case so that the belief lingers on in the next moment, thus either showing that SAFETY is false, or else demonstrating that the next moment is no longer nearby the previous one in the relevant epistemic sense.

\footnotetext{
${ }^{30}$ Note that if one points out that it is at least possible that in a scenario like this, there is belief at the next moment, then that is certainly true. But in order for the two cases to be near, it has to be that the belief at the next moment is "similarly based." For instance a person who irrationally always believed the chip was red would continue to belief the chip was red even as it turned blue. But this doesn't immediately entail that they cannot see that the chip is red, and so does not entail that they cannot know that the chip is red (provided that knowledge is the most general factive attitude).
} 
The third and final response I want to give points out another way in which anti-luminosity type arguments rely on premises that jointly predict some implausible consequences. Consider the sorts of phenomenal properties of most interest in the philosophy of perception: those phenomenal properties that correspond to the fine grained representation of color. For instance, in the above phenomenal continua case one has a sequences of phenomenal properties: $\operatorname{red}_{121}, \operatorname{red}_{120}$ and so on. Can one know that one has them at all? I suspect the intuitive answer is: yes of course! Even those who think we sometimes have a phenomenal property while failing to know that we do will accept that we often know that we have the specific phenomenal properties that we in fact have. But if the anti-luminosity argument is correct, there is what appears to be an equally compelling case that we can never know that we have these specific phenomenal properties. For suppose we can construct a sequence of cases $\alpha_{1}, \ldots, \alpha_{n}$ that is problematic for the phenomenal property red (by which I mean something like the experience of red). Then there is some case $\alpha_{i}$ such that in $\alpha_{i}$ one has red and in the next moment one does not. Now if one knows that one has red, then by (4) it should follow that in $\alpha_{i+1}$ one believes one has red. The justification for this appeal is again the supposed imprecise nature of the dispositions governing our beliefs. But note that in $\alpha_{i}$, one also has some highly specific phenomenal property red' that is a determinate of red. Since red' is highly specific, we can suppose that in the next moment, one lacks it and instead has some other indiscriminable phenomenal property red". Now I don't see why we should suppose that knowledge of red requires belief in the next moment without also requiring that knowledge of red' requires belief in the next moment as well. The same motivation can be applied to get this conclusion. Since our highly specific phenomenal properties are constantly changing, one is red' only for a moment before one acquires a different, but perhaps barely discriminable, phenomenal property. So if knowledge of the determinate phenomenal property requires belief in the next instance, then given SAFETY, one would never know one had red' in any ordinary situation.

One could just embrace this conclusion. It suffices that we often have knowledge of our determinable phenomenal properties. Knowledge of their determinates is just too hard a 
feat for normal adult humans. I sort of have a hard time believing that, though. When I look around the room, there seems to be some highly specific phenomenal features I have, and it seems to me that I know that I have them. I might express this knowledge by saying to myself, at each moment, "Things are like this" or "This is how things are," using the demonstrative to refer to the highly specific phenomenal properties I had in that instant. Thus if we do have such knowledge generally, that suggests something is amiss with the antiluminosity argument, since parallel arguments can be constructed that lead to the conclusion that we lack knowledge in situations in which we do not 3132

\section{Conclusion}

In this paper I've set out (part of) the case for the thesis that to be phenomenal is to be consistent and luminous. There is much more to be said for and against this thesis. Some possible future avenues for investigation would be a fuller accounting of the costs and benefits as compared to other first order theories of the phenomenal. There are also further applications of the thesis to the philosophy of action, the philosophy of understanding and the philosophy of emotions that are worth investigating. ${ }^{33}$ There are no doubt many other objections that I could have addressed. For instance, the thesis likely has some bearing on

\footnotetext{
${ }^{31}$ Amia Srinivasan (2015) grants that someone who accepts a tight connection between the phenomenal and the doxastic avoids Williamson's argument as it is formulated above. However there is a more sophisticated version of the argument that is closer to Williamson's original formulation that she takes to avoid the pitfalls of the simpler version. Unfortunately responding to Srinivasan's formulation of the argument will have to wait.

${ }^{32}$ I want to briefly respond to one further objection here that has been raised by an anonymous reviewer. Consider the property of being such that, if one has that property, one knows that one has it. Call that property ' $P$ '. Thus if $P$ exists, then

$P=$ being such that if one has $P$, one knows that one has $P$.

Clearly if such a property exists, it is luminous. For suppose that one has $P$. Then one is such that if one has $P$, one knows that one has $P$. And so one knows that one has $P$. But I don't think there is any such property. Here is why: there is at least one thing that doesn't know anything. The table that my computer is sitting on, for example, does not know anything. Call this table ' $t$ '. Now if $t$ does not have $P$, then $t$ is not such that if $t$ has $P, t$ knows that $t$ has $P$. Since the negation of a conditional is equivalent to the conjunction of its antecedent with the negation of its consequent, it follows that $t$ has $P$ and $t$ does not know that $t$ has $P$. In particular, $t$ has $P$. So if $t$ does not have $P, t$ has $P$. This (classically) implies that $t$ has $P$. So $t$ is such that if $t$ has $P, t$ knows that $t$ has $P$. So $t$ knows that $t$ has $P$. So $t$ knows something. But surely it doesn't!

${ }^{33}$ Basically since phenomenal properties play a very distinctive role on this theory, there is potential application of the theory in any area where knowledge itself plays a distinctive role.
} 
the question as to whether experiential content is "conceptual" or "nonconceptual," though spelling out what the connection is precisely is not as straightforward as it might seem. Here, I only hope to have shown that the thesis is interesting and worth taking seriously as a theory of the phenomenal.

\section{ACKNOWLEDGEMENT}

I would like to thank Brian Cutter, Curtis Franks and Jeff Speaks for reading and providing feedback on earlier drafts of this paper, and also the anonymous reviewers who provided numerous helpful comments and suggestions.

\section{REFERENCES}

Antony, Michael. 2006. "Papineau on the Vagueness of Phenomenal Concepts," Dialectica 60(4): 475-483.

Antony, Michael. 2008. "Are our Concepts COnscious StATE and COnscious CREATURE vague?" Erkenntnis 68: 239-263.

Armstrong, D.M. 1968a. A Materialist Theory of the Mind. Routledge.

Bacon, Andrew. 2014. "Giving your Knowledge Half a Chance. Philosophical Studies (2):1-25.

Bacon, Andrew. 2018. Vagueness and Thought. Oxford University Press.

Barnett, David. 2011. "Does vagueness exclude knowledge?" Philosophy and Phenomenological Research, 82(1): 22-45.

Berker, Selim. 2008. "Luminosity Regained." Philosophers' Imprint, 8(2): 1-22.

Bourget, David and Mendelovici, Angela, "Phenomenal Intentionality", The Stanford Encyclopedia of Philosophy (Spring 2019 Edition), Edward N. Zalta (ed.),=.

Byrne, Alex. 1997. "Some Like it Hot: Consciousness and Higher-Order Thoughts. Philosophical Studies 86 (2):103-129.

Byrne, Alex. 2001. "Intentionalism Defended." Philosophical Review, 110(2): 199-240.

Carruthers, Peter. 2005. Consciousness: Essays From a Higher-Order Perspective. Oxford University Press UK. 
Carruthers, Peter, "Higher-Order Theories of Consciousness", The Stanford Encyclopedia of Philosophy (Fall 2016 Edition), Edward N. Zalta (ed.).

Chalmers, David. 2004. "The Representational Character of Experience." In Leiter 2004, pp.153-181.

Dretske, Fred. 1993. "Conscious Experience." Mind 102 (406):263-283.

Dretske, Fred. 2000. Perception, Knowledge and Belief: Selected Essays. Cambridge University Press.

Dretske, Fred. 2003. "Experience as Representation." Philosophical Issues, 12(1):67-82.

Dretske, Fred. 2006. "Perception Without Awareness." in Gendler and Hawthorne 2006, pp. $147-180$.

Dorr, Cian. 2003. "Vagueness Without Ignorance." Philosophical Perspectives, 17(1):83-113.

Dorr, Cian. 2016. "To Be F Is To Be G." Philosophical Perspectives 30 (1): 39-134.

Feldman, Richard and Conee, Earl. 1985. "Evidentialism." Philosophical Studies 48 (1):15 34.

Gendler, Tamar Szabo and Hawthorne, John (eds.). 2002. Conceivability and Possibility. Oxford University Press.

Greco, Daniel. 2014. "Iteration and Fragmentation." Philosophy and Phenomenological Research, 88(1):656-673.

Hawthorne, John and Stanley, Jason (2008). "Knowledge and Action." Journal of Philosophy $105(10): 571-590$.

Huemer, Michael. 2001. Skepticism and the Veil of Perception. Lanham: Rowmanand Little field.

Huemer, Michael. 2007. 'Compassionate Phenomenal Conservatism'. Philosophy and Phenomenological Research 74: 30-55.

Leiter, Brian (ed) 2004. The Future for Philosophy. Oxford University Press.

Levin, Janet. 2018. "Functionalism." The Stanford Encyclopedia of Philosophy (Fall 2018 Edition), Edward N. Zalta (ed.), URL = https://plato.stanford.edu/archives/fall2018/entries/functionalism/, accessed April 
30, 2019.

Lewis, David. 1995. "Should a Materialist Believe in Qualia?" Australasian Journal of Philosophy, 73(1): 140-44.

Lewis, David. 1996. "Elusive Knowledge." Australasian Journal of Philosophy 74 (4): 549567.

Lewis, David. 1999. Letter to Timothy Williamson, 21 May 1999. Available on the Age of Metaphysical Revolution website, letter of the month, October 2018. <http:// www.projects.socialsciences.manchester.ac.uk/lewis/letter-of-the-monthnovember-2018/>, accessed April 30, 2019.

Lycan, William. 1996. Consciousness and Experience. MIT Press.

Montague, Michelle. 2016. The Given: Experience and its Content. Oxford University Press.

Murray, Dylan ; Sytsma, Justin and Livengood, Jonathan 2013. "God knows (but does God believe?)." Philosophical Studies 166 (1):83-107.

Myers-Schulz, Blake and Schwitzgebel, Eric (2013). Knowing That P without Believing That P. Nô̂s 47 (2):371-384.

Nagel, Jennifer. 2013. "Knowledge as a Mental State." Oxford Studies in Epistemology 4:275310.

Neander, Karen. 1998. "The Division of Phenomenal Labor: A Problem for Representational Theories of Consciousness." Noûs 32 (S12):411-434.

Pautz, Adam. 2010. "Why Explain Visual Experience in Terms of Content?" In Nanay 2010, pp 254-309.

Pryor, James. 2000. "The Skeptic and the Dogmatist." Nô̂s 34 (4):517- 549.

Rayo, Augustin 2013. The Construction of Logical Space. Oxford University Press.

Rose, David and Jonathan, Schaffer. 2013. "Knowledge Entails Dispositional Belief." Philosophical Studies 166:19-50.

Rosenthal, David. 2004. "The Nature of Consciousness." Mind 113(451):581-588.

Rosenthal, David. 2005. Consciousness and Mind. Oxford University Press UK.

Schellenberg, Susanna. 2013. "Experience and Evidence.” Mind 122 (487):699-747. 
Schellenberg, Susanna. 2016. "Phenomenal Evidence and Factive Evidence." Philosophical Studies 173 (4):875-896.

Siegel, Susanna. 2010. The Contents of Visual Experience. Oxford University Press.

Speaks, Jeff. 2015. The Phenomenal and the Representational. Oxford University Press.

Srinivasan, Amia. 2015. "Are We Luminous?" Philosophy and Phenomenological Research, 90(2):294-319.

Stalnaker, Robert. 1999. Context and Content: Essays on Intentionality in Speech and Thought. Oxford University Press UK.

Simon, Jonathan. 2017. "Vagueness and Zombies: Why 'phenomenally conscious' has no Borderline Cases," Philosophical Studies 174: 2105-2123.

Stoljar, Daniel. 2016. "Introspection and Necessity." Nô̂s, 51(1).

Tye, Michael. 1995. Ten Problems of Consciousness. Cambridge, MA: Bradford Books/MIT Press.

Van Inwagen, Peter. 1998. "Modal epistemology." Philosophical Studies 92 (1):67-84.

Weatherson, Brian. 2004. "Luminous Margins." Australasian Journal of Philosophy, 82(3): 373-383.

Williamson, Timothy. 1994. Vagueness. Routledge.

Williamson, Timothy. 1995. "Is Knowing a State of Mind?" Mind 104 (415):533-65.

Williamson, Timothy. 2000. Knowledge and its Limits. Oxford University Press.

Williamson, Timothy. 2016. "Modal science." Canadian Journal of Philosophy 46 (4-5):453492.

Wittgenstein, Ludwig. 1953. Philosophical Investigations, 4th edition, 2009, P.M.S. Hacker and Joachim Schulte (eds. and trans.), Oxford: Wiley:Blackwell. 